\title{
La transcripción fonética en estudios dialectales: propuestas en el caso del yeísmo*
}

\author{
Phonetic Transcription in Dialectical Studies: \\ Remarks on "yeísmo"
}

\author{
Assumpció Rost Bagudanch
}

Universitat de les Illes Balears

RESUMEN: Los atlas dialectales del español surten de una información abundantísima acerca de las variantes fonéticas del yeísmo. Sin embargo, el método más habitual de recogida de los datos, basado en la interpretación perceptiva del encuestador, puede llevar a ambigüedades o a confusiones. En el presente trabajo no solo se demuestra que el uso de técnicas de análisis fonético acústico permite una categorización de los estímulos más objetiva sino que su empleo también hace posible llegar a una clasificación más racional y sistemática de los alófonos detectados.

Palabras clave: Dialectología, atlas dialectales, fonética experimental, análisis acústico.

ABSTRACT: Spanish dialect atlases provide an abundance of information on the phonetic variations of the yeísmo. However, the most commonly used collection method, based on the interviewer's perceptive interpretation, can lead to ambiguities or confusion. The present essay not only proves that the use of acoustic phonetic analysis techniques allows for a more objective categorization of the stimuli, but its use also makes a more rational and systematic classification of the detected allophones possible.

Keywords: Dialectology, Dialectal Atlas, Experimental Phonetics, Acoustic Analysis.

\footnotetext{
* Esta investigación ha sido posible gracias a la ayuda del Ministerio de Educación y Cultura (proyecto FFI2008-06324-C02-02/FILO).
} 


\section{INTRODUCCIÓN}

Que la lengua española tiene un número de hablantes cercano a los 400 millones es algo sabido. Que no todos estos hablantes emplean su idioma de la misma manera, también. Las diferencias existentes son las que llevan a la subdivisión del sistema linguiístico en dialectos y subdialectos, que se caracterizan por unos usos particulares en una determinada área geográfica. De hecho, uno de los aspectos que permite distinguir de forma más evidente estas variantes lingüísticas es la pronunciación, la fonética. Por este motivo, no es de extrañar que gran parte de las descripciones dialectales se hayan centrado tradicionalmente en establecer los rasgos fónicos que identifican las diversas zonas dialectales (sin olvidar otras propiedades idiosincrásicas como puede ser el léxico de cada región). En este sentido, baste mencionar a Zamora Vicente (1967), Alcina y Blecua (1975), Alvar (1996a, 1996b), Lipski (1996) o Fontanella de Weinberg (2000).

Una de las cuestiones que más llaman la atención cuando uno se dedica al estudio de las variantes fonéticas dialectales es el tratamiento de su definición como sonido y, paralelamente, su representación gráfica. Podría parecer que se trata de un aspecto menor en el análisis de la variación; sin embargo, no creemos que sea así. En efecto, la consideración de un alófono concreto como un tipo de fono u otro puede modificar el resultado de estudios ulteriores y más si su categorización puede resultar algo ambigua. También las formas de transcripción fonética pueden contribuir a crear confusiones, de lo que hay abundantes ejemplos en la bibliografía.

Por lo tanto, se podría decir que estamos en una situación en la que no se acaba de apreciar una homogeneidad de criterios clara, lo que lleva a plantearse una serie de preguntas clave para entender cómo se clasifican (o podrían clasificarse) las realizaciones fonéticas documentadas a nivel dialectal. Metodológicamente, parece obvio que los parámetros que permiten establecer las distinciones entre alófonos deberían ser muy precisos; del mismo modo, habrían de estar bien definidos los criterios empleados para asociar cada sonido a un tipo de manifestación fonética y, evidentemente, cuáles van a ser la nomenclatura y el sistema de transcripción utilizados: o el sistema de la Revista de Filología Española (RFE, a partir de aquí) o el alfabeto fonético internacional (AFI) ${ }^{1}$.

Sin embargo, la realidad apunta a la existencia de múltiples soluciones y a criterios no siempre homogéneos, lo que dificulta sobremanera la comparación entre obras, áreas y, en definitiva, fenómenos. El yeísmo es un caso para-

\footnotetext{
${ }^{1}$ En algunas obras se advierte el uso cruzado de los dos sistemas de representación gráfica, especialmente en lo que a las consonantes vibrantes se refiere. En nuestro caso, se emplea el AFI dado que es el predominante en trabajos recientes de fonética y fonología y de dialectología, incluso a nivel prescriptivo.
} 
digmático de ello puesto que la revisión de la bibliografía evidencia una falta de uniformidad excepcional en el tratamiento de las variantes detectadas.

De hecho, con la finalidad de dotar de mayor coherencia y de ilustrar convenientemente nuestro punto de vista, se ha decidido tomar el yeísmo como punto de partida, dadas las serias dificultades que ofrece para establecer paralelismos y equivalencias entre las diferentes obras que lo abordan. Como se verá, no solo se han podido detectar diversas soluciones para representar los alófonos del cuestionado fonema $/ K /^{2}$ sino que a esta dificultad se añade cuál debe ser la transcripción de la realización palatal más común en la actualidad: [j], [j] ], [j] o [j] (cfr. Martínez Celdrán, 2004 o Martínez Celdrán y Fernández Planas, 2007: 58-63).

Así pues, para obtener el corpus de datos de este trabajo se ha analizado, por una parte, la representación gráfica y la consideración fonética de las variantes que se encuentran en los atlas linguísticos regionales y, por otra, las de cierta bibliografía relevante que emplea la misma metodología que estos. La lista de obras de la que se ha partido viene detallada en la tabla 1. A esta primera parte de análisis, sigue una reflexión sobre las características de los alófonos registrados, para lo que se han empleado técnicas de análisis experimental del habla. Por último, se profundiza en la necesidad de aunar criterios y de emplear una serie de distinciones que puedan ser contrastadas empíricamente.

\section{ATLAS LINGÜÍSTICOS:}

- Atlas Lingüístico y Etnográfico de las Islas Canarias (ALEICan), Alvar (1975)

- Atlas Lingüístico y Etnográfico de Aragón, Navarra y La Rioja (ALEARN), Alvar (1979-1983)

- Atlas Lingüístico-Etnográfico de Colombia (ALEC), Flórez (1981-1983)

- Atlas Lingüístico de México, Lope Blanch (1990)

- Atlas Lingüístico de Castilla y León, Alvar (1999)

- Atlas Lingüístico y Etnográfico de Andalucía (ALEA), Alvar (1923-2001a)

- Atlas Lingüístico y Etnográfico de Cantabria (ALECant), Alvar (1923-2001b)

- Atlas Lingüístico (y etnográfico) de Castilla-La Mancha (ALeCMan), García Mouton y Moreno Fernández (2003)

- Cartografía lingüística de Extremadura, González Salgado (2005-2010)

OTRAS OBRAS: Alvar (2000a, 2000b, 2001a, 2001b)

TABLA 1. Relación de obras a partir de las cuales se ha obtenido el corpus de realizaciones fonéticas base de este trabajo (el orden es cronológico según el momento de publicación)

2 Tradicionalmente, las descripciones del sistema fonético del español siguen contemplando la existencia de $/ K /$ como fonema, aunque datos recientes parecen apuntar a que habría desfonologizado a favor de uno carente de lateralidad (cfr. Hualde, 2005: 180). El volumen de fonética de la nueva gramática de la RAE habla de la existencia de dos subsistemas, uno distinguidor y otro yeísta (cfr. RAE, 2011: §6.2) aunque también advierte que "en la mayor parte del dominio hispanohablante ha desaparecido la distinción fonológica” (RAE, 2011: 194). De cualquier forma, para no caer en confusiones con $/ \mathrm{j}_{\mathrm{r}}$ / en otros contextos, aquí se ha optado por seguir contemplando el fonema lateral palatal. 
1.1. Algunas consideraciones previas sobre el yeísmo y su transcripción fonética

Antes que nada, resulta imprescindible revisar algunos de los problemas que plantea el yeísmo en cuanto a su naturaleza y su representación gráfica. Como se sabe, este fenómeno consiste en la confusión de la lateral palatal $[\Lambda]$ con un sonido consonántico palatal sin rasgo de lateralidad, como se desprende de Navarro Tomás (1982: 134-135, §124), Quilis (1993: 314-315) o Hualde (2005: 180). Este fono puede venir caracterizado de formas diferentes según los autores. Algunos hablan de una consonante fricativa palatal (Quilis, 1981, 1993 o RAE, 2011: 221), otros de una aproximante. El quid de la cuestión es qué significan estos términos, que hacen referencia a las propiedades articulatorias y acústicas del segmento.

Las consonantes fricativas se articulan con un estrechamiento en el paso del aire, lo que supone que se produce una fricción muy característica en su salida
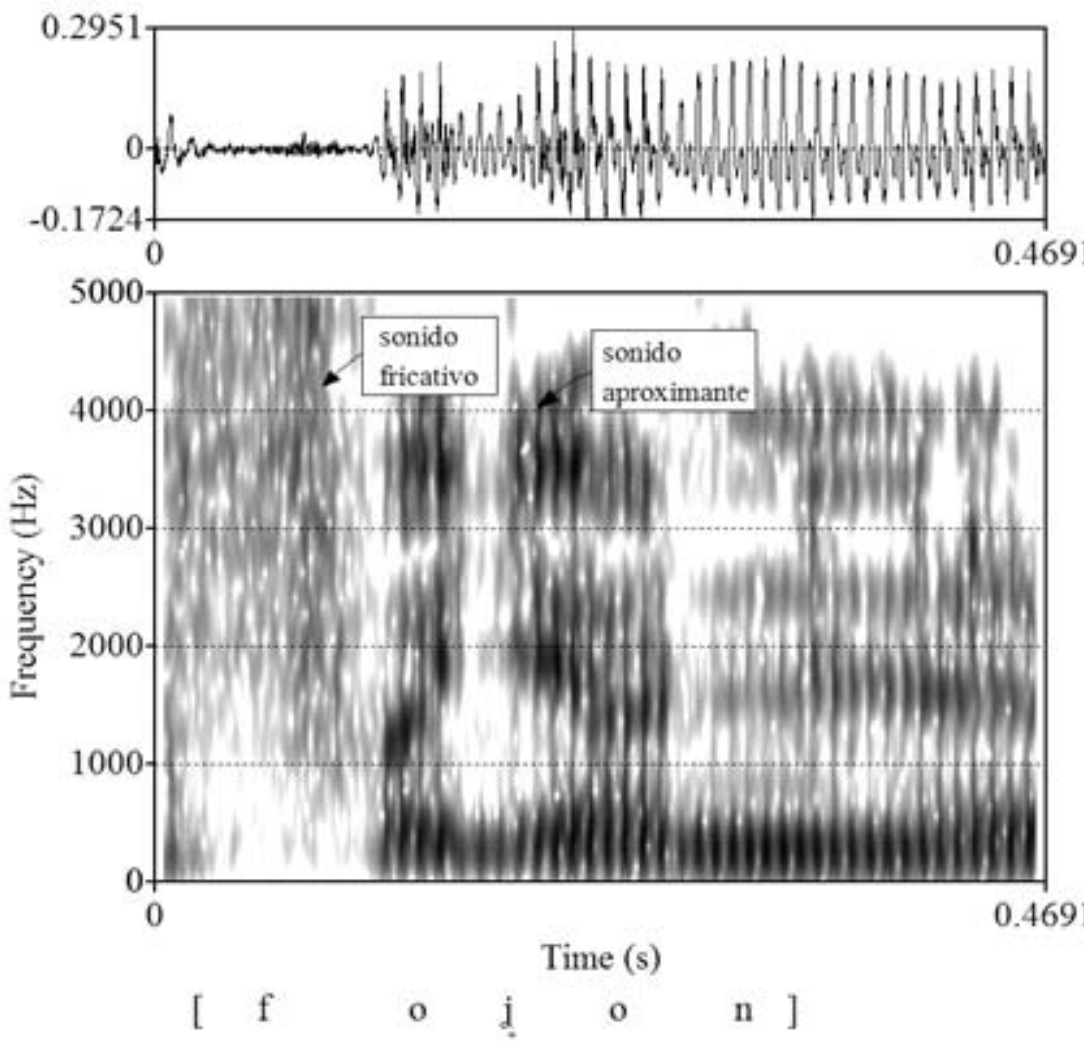

FIGURA 1. Oscilograma y espectrograma de la palabra follón. 
al exterior. En estos casos, acústicamente, tal fricción es apreciable por una zona de energía dispersa que puede observarse netamente en los espectrogramas, tal como puede advertirse en el sonido correspondiente a /f/ que aparece en la figura 1. En cambio, en las aproximantes esta fricción no se da; de hecho, se trata de consonantes muy distintas que presentan estructura formántica, algo de lo que las fricativas carecen. En la misma imagen a la que se aludía anteriormente, $\left[\dot{j}_{\tau}\right.$ ] sería un ejemplo claro de ello. Desde el punto de vista de la fonética acústica, la diferencia entre ambas es considerable. El problema aquí es dilucidar a qué tipo de sonido se hace referencia, de modo genérico, en las obras dialectales.

A tenor de los ejemplos (con espectrogramas) que ofrecen autores como Quilis (1993: 261, 314 y ss.) al centrarse en el fenómeno yeísta, parece ser que se está ante una consonante de tipo aproximante que podría presentar distintos alófonos en función del contexto en que se halle: en posición intervocálica se trataría efectivamente de una aproximante, mientras que tras pausa, nasal o [1], se correspondería con una manifestación acústica reforzada de tipo oclusivo, tal como ocurre con /b/, /d/ y /g/ (cfr. Martínez Celdrán y Fernández Planas, 2007: 62, por ejemplo) ${ }^{3}$.

Sin embargo, suelen presentarse diversas formas de transcripción para esta consonante. Una parte muy importante de los trabajos publicados ha adoptado el sistema de la $R F E$ y, en él, esta consonante suele figurar como [y]. El AFI, por su parte, contempla un símbolo [j] para la semiconsonante palatal y otro, [j], para una fricativa palatal. El problema es que ninguno de ellos indica una aproximante, que supondría el punto intermedio entre ambas. Por este motivo, Martínez Celdrán (2004) propone que se emplee el diacrítico [_] ('más adelantado') junto a la grafía correspondiente a la realización fricativa: es una manera sencilla y eficaz de distinguir los tres sonidos siguiendo el mismo patrón que el resto de aproximantes del español.

No obstante, la complejidad del fenómeno yeísta no se cierra con dirimir si se está ante un elemento de tipo aproximante o fricativo. En efecto, como demuestran las 60 soluciones (aproximadamente) que se pueden documentar en las obras referenciadas en la tabla 1 (vid. supra), en el dominio linguiístico del español se han podido detectar infinidad de variantes que se organizan a lo largo de un continuum que contempla desde realizaciones con rasgo lateral en un extremo hasta otras de tipo africado y oclusivo, en el otro, tal como se puede apreciar en la figura 2. La diversidad de posibilidades que se observa hace que

\footnotetext{
${ }^{3}$ Pese a que la $\operatorname{RAE}(2011: \$ 5.4$ y $5.4 \mathrm{~g}$ ) reconoce que este elemento posee una estructura formántica característica que lo diferencia de modo evidente del resto de consonantes obstruyentes fricativas, se sigue defendiendo que esta es su naturaleza, incluso en el caso del yeísmo (cfr. RAE, 2011: §6.4d y sigs.). De todos modos, sí se menciona que puede presentar realizaciones aproximantes en determinadas zonas.
} 
su sistematización resulte primordial para la comprensión del alcance de este proceso de cambio, que avanza muy rápido y por cauces que, en ocasiones, sorprenden. Por este motivo se ha creído oportuno centrar en él las consideraciones que siguen, las cuales podrían llegar a verse como una especie de reflexión en voz alta sobre su disposición actual.

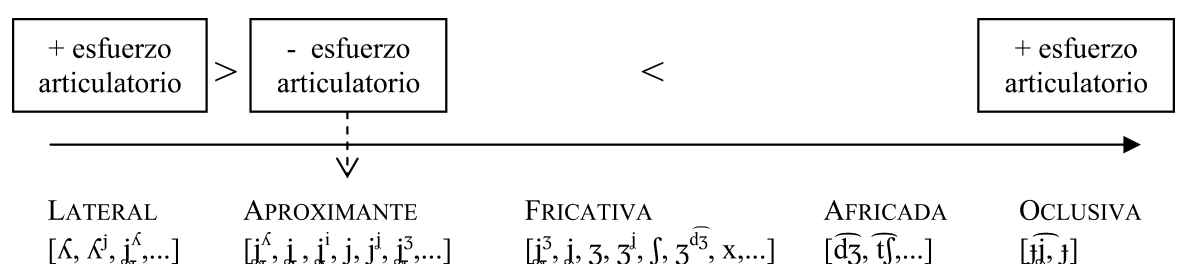

FIGURA 2. Representación del continuum de realizaciones fonéticas del yeísmo.

\section{LA INFORMACIÓN FONÉTICA EN LOS COMPENDIOS DIALECTALES}

A los problemas que, ya de por sí, conlleva la naturaleza fonética de $/ K /$ se añade el de su tratamiento en la bibliografía de corte dialectal. No es este un aspecto menor de la cuestión sino más bien todo lo contrario. Como se ha visto en el apartado anterior, el fonema lateral palatal puede presentar alófonos muy diversos, pese a que el más frecuente sería el de una aproximante palatal sonora. En consecuencia, resulta imprescindible averiguar cómo se da cuenta de tal nivel de variación en los estudios diatópicos y qué criterios rigen su representación gráfica con el fin de determinar si esta información se presenta según unos principios unificados o lo hace de forma dispersa. No debe olvidarse que uno de los mayores logros de estos trabajos es el de ofrecer un catálogo de las soluciones existentes en un territorio concreto y que, en consecuencia, deberían dar cuenta de características acústicas y articulatorias claramente identificables para cualquier investigador que los tome como punto de referencia.

Así pues, resulta muy instructivo consultar la introducción de las obras revisadas, ya que es donde la mayor parte de ellas presenta la metodología utilizada para la recogida de los datos. En lo referente a la parte fonética, únicamente suele precisarse que los encuestadores son expertos en la distinción de los sonidos a nivel perceptivo y que son especialistas en el campo de la dialectología. Lo habitual es que, a partir de los resultados generados por las preguntas de la encuesta, se recojan por escrito una serie de materiales, como expone Alvar en la introducción al ALECant (1923-2001b:14):

Las encuestas las hice con dos abnegados colaboradores [...], doctores en Lingüística Hispánica. [...] intentamos preguntar parcelas precisas, pero, aun- 
que para el explorador sea peor limitarse a un aspecto del conjunto, resulta mejor por otra parte por cuanto asegura certeza para identificar las respuestas y uniformidad en las transcripciones [...]. Así, pues, la uniformidad de criterio queda bien respetada: el mismo explorador preguntó de manera constante fonética, morfología, sintaxis y parte del léxico, con lo que siempre estarán esos rasgos fonéticos como muestra del habla.

Es decir, los investigadores agrupan los segmentos en categorías fonéticas según su percepción auditiva, guiándose por su competencia como hablantes (o mejor dicho, como oyentes). En prácticamente ningún caso se hace referencia a pruebas de tipo empírico que permitan objetivar claramente a qué manifestación fonética pertenece un estímulo concreto. La conclusión parece apuntar a una valoración más o menos subjetiva del input por parte del encuestador: dependiendo de la capacidad de cada individuo, este puede ser más o menos escrupuloso en sus apreciaciones y puede clasificar de un modo u otro los datos que haya obtenido. La excepción la constituyen los trabajos recientes de Alvar, que incluyen explicaciones a nivel acústico para dar cuenta de las diversas categorías fonéticas (cfr. Alvar, 2000a, 2000b, 2001a, 2001b) y los atlas hispanoamericanos: tanto el ALEC como el Atlas Lingüístico de México recogen grabaciones que han sido analizadas y cuyos datos constituyen una parte de los resultados fonéticos.

Cabe comentar que no se duda, en ningún momento, de la profesionalidad y del entrenamiento de estos investigadores; sin embargo, no parece descabellado pensar que, por mucho acuerdo explícito al que se haya llegado a la hora de establecer unos criterios preliminares, las modulaciones a las que está sujeta el habla (en ocasiones incluso por las características físicas del emisor) pueden dar lugar a matices diferentes que quedan a la interpretación del receptor de la señal. Esto explicaría, sin duda, las caracterizaciones de los sonidos que aparecen en los inventarios previos a los mapas, en las que se llega a una precisión en el detalle muy encomiable pero que puede resultar algo confusa, tal como se muestra en los ejemplos de (1), referidos a algunas realizaciones fonéticas de $/ K /^{4}$ :

(1) a. fricativa corono-alveolar plana sorda con rehilamiento (ALEA);

b. palatal fricativa débilmente rehilada ensordecida con tendencia a semiconsonante (Atlas Lingüístico de México);

c. palatal central sonora muy abierta con tendencia a semivocal (ALECant).

Precisamente este aspecto subjetivo es el que hace posible que los inventarios de sonidos que se recogen en las obras revisadas no siempre concuerden entre sí, lo que implica una evidente dificultad a la hora de establecer equivalencias y comparaciones. Los problemas en este sentido se deben principalmen-

\footnotetext{
${ }^{4}$ Los ejemplos que se ofrecen siempre se presentan por orden cronológico según el momento de publicación de la obra a la que pertenezcan.
} 
te a dos factores: o bien a la descripción de los rasgos fonéticos de los alófonos o bien a su representación gráfica. En cuanto al primero de ellos, el hecho de carecer de una terminología unificada, exenta de elementos sujetos a interpretaciones individuales, acarrea desajustes a la hora de establecer correspondencias entre manifestaciones fonéticas. En ocasiones, la identificación se resuelve apelando al sentido común, mientras que, en otras, no resulta tan sencillo, como puede advertirse en (2) y (3):

(2) $[\hat{\mathrm{s}}]$ a. "africada palatal sorda" (Atlas lingüístico de Castilla y León, ALECant, ALeCMan);

b. "palatal africada sorda, de momentos oclusivo y fricativo relativamente equilibrados" (ALEC);

(3) $\left[\begin{array}{c}\check{z} \\ \text { ] }\end{array}\right.$ a. "alveolo-prepalatal central muy rehilada y sin labialización" (ALEICan, ALEA);

b. "prepalatal central muy rehilada" (González Salgado 2005-2010);

c. "palatal central fricativa con realización adelantada" (ALeCMan).

Por otra parte, la mayor dificultad quizás se deba a los criterios de transcripción, que no siempre resultan homogéneos. En efecto, es posible encontrar un mismo símbolo para realizaciones diferentes dependiendo de quien firme la obra o, al contrario, un mismo alófono transcrito de formas diversas. Algunos ejemplos del primer tipo se reseñan en (4), (5) y (6), mientras que otros del segundo, en (7) y (8):

(4) [ž] a. "fricativa prepalatal sonora" (ALEANR, ALEC, ALECant, Alvar 2001b y ALeCMan);

b. "fricativa palatal sonora" (Atlas lingüístico de México, ALEA, González Salgado 2005-2010);

c. "dentoalveolar coronal fricativa sonora asibilada y rehilada" (Alvar, 2001b);

(5) [ŷ] a. "palatal central sonora ligeramente rehilada" (ALECant);

b. "africada palatal central sonora" (ALEICan, Atlas de Castilla y León, ALEANR, ALEC, Atlas lingüístico de México, ALEA, Alvar, 2001b, ALeCMan, González Salgado, 2005-2010);

(6) [ŷ̀] a. "palatal central africada ensordecida" (Alvar, 2001b, ALeCMan); b. "prepalatal fricativa semi-sonora" (Alvar, 2001b).

(7) [y̌]: "palatal central ligeramente rehilada semisonora" (Alvar, 2001b); [y̆]: "palatal central ensordecida débilmente rehilada" (Atlas lingüístico de México);

(8) [ŷ̀]: "palatal central sonora ligeramente rehilada" (ALeCMan);

[ŷ]: "palatal central sonora ligeramente rehilada" (ALECant);

[y̆]: "palatal central sonora ligeramente rehilada" (ALEICan, Atlas de Castilla y León, ALEARN, Atlas lingüístico de México, ALEA, Alvar, 2001b, González Salgado, 2005-2010). 
La sensación que se desprende de todo ello es la de una cierta desorganización; una falta de sistematización en los datos (valiosísimos por otro lado) que complica innecesariamente el estudio de la variación dialectal a nivel fonéticofonológico. Otro elemento que contribuye a ello es el hecho de que, en los últimos tiempos, se ha tendido a recurrir al AFI antes que al alfabeto de la $R F E$, ya que facilita sobremanera la comparación con otros sistemas lingüísticos en los que este no se emplea (cfr. Moreno Fernández, 2009) o los últimos trabajos de la RAE, incluyendo en cierto modo la nueva ortografía (RAE, 2010) y, por supuesto, la nueva gramática (RAE, 2011). En estos casos, la fijación de las correspondencias todavía puede ser más caótica por las particularidades de los diferentes sistemas de notación (en el uso de diacríticos, por ejemplo).

En este sentido, quizás el empleo de técnicas complementarias a la percepción de los estímulos podría arrojar algo de luz en este conglomerado de caracterizaciones, lo que derivaría en una mayor homogeneidad en el uso de los símbolos gráficos. Así pues, interesa averiguar qué elementos consignados entre los rasgos de los diversos alófonos son realmente objetivos y, por lo tanto, pueden suponer diferencias importantes entre realizaciones fonéticas. Ciertamente el detalle es importante en el estudio de la variación, pero también lo es la coherencia en los datos que se trata de analizar.

\section{LA NATURALEZA DE LOS SONIDOS}

Precisamente con la finalidad de lograr esta coherencia, es primordial conocer las características fonéticas que realmente puedan ser consideradas relevantes, unas características que deben venir establecidas por medios experimentales, puesto que son los que, en principio, deben garantizar su objetividad. Como explican las obras revisadas, el punto de partida sobre el que se produce la clasificación de los alófonos en el corpus es la discriminación por parte del encuestador. Lógicamente, este reconoce una serie de propiedades de tipo articulatorio y acústico en la señal que recibe, que son las que se emplean para proceder a la clasificación de los sonidos. De hecho, la misma descripción fonética suele combinar elementos procedentes de la articulación con otros de naturaleza acústica. Sin embargo, en el momento de establecer unos parámetros nítidos y objetivables resulta más claro acudir a los recursos que ofrece la fonética acústica. La razón de ello es simple: el investigador recibe la señal por esta vía y es a través de sus rasgos acústicos que llega a las conclusiones que le permiten identificar el input como una $\mathrm{u}$ otra categoría fónica.

Ciertamente, esta señal se genera necesariamente en la articulación y no es menos cierto que pequeñas variaciones en esta pueden provocar modificaciones importantes en aquella, por lo que podría parecer conveniente comprobar expe- 
rimentalmente este extremo. No obstante, hay que tener presente la finalidad de las encuestas; a saber, que unos individuos puedan responder de la forma más natural posible a una serie de cuestiones. El estudio articulatorio de estas respuestas implicaría el uso de una serie de técnicas (palatogramas, por ejemplo) que impedirían la espontaneidad de las mismas. Por lo tanto, parece más apropiado pensar en un tipo de análisis a posteriori que no suponga entorpecer la labor del encuestador. Por otra parte, pese a que este puede tener intuiciones más o menos exactas sobre la posición de los órganos articuladores en cada caso, no puede tener una seguridad absoluta, máxime cuando se ha comprobado que estrategias articulatorias distintas pueden llevar a un resultado acústico muy similar, como reconocen Delattre (1967) o Malmberg (1971: 75) (en Quilis, 1981:20-22 y 1993:121-122).

En consecuencia, el método menos invasivo y más fiable para el estudio de los resultados obtenidos es el análisis acústico. Recurrir a oscilogramas y espectrogramas sería una buena medida para determinar, con una base científica experimental, las propiedades de los alófonos registrados y en qué categoría fónica se deben incluir. Por otra parte, permiten valorar debidamente algunas de las observaciones consignadas en los atlas, tales como el grado de abertura en caso de sonidos de tipo aproximante (abierto, muy abierto o extremadamente abierto), el de ensordecimiento o la intensidad del rehilamiento. Estos procedimientos van a ser útiles para poder demostrar la relación entre las distinciones presentes en esta clase de obras y los rasgos fonéticos a los que hacen referencia. Justamente por este motivo se ha decidido estudiar una serie de rasgos acústicos de las realizaciones documentadas en el caso que nos ocupa, el yeísmo, especialmente en lo referente a algunas de las características que más se han puesto de relieve: el grado de abertura del sonido en los que presentan estructura formántica, la sonoridad, la presencia o ausencia de rehilamiento y la existencia de una fase de cierre de los articuladores (oclusión).

Para ello, se han empleado los datos procedentes de un experimento acústico en el que se ha grabado a tres informantes varones castellanohablantes. Estos locutores debían leer una serie de párrafos en los que se habían insertado términos que contenían los elementos que interesaba analizar en cada caso. Esta grabación se ha realizado en una cámara insonorizada del laboratorio de fonética de la Universitat de Girona con una grabadora Marantz PMD670 y un micrófono Shure Unydine 5155D. Para la confección del corpus, se han tenido en cuenta los rasgos fonéticos arriba mencionados (grado de abertura, sonoridad, rehilamiento y oclusión), para lo que se ha procurado generar los contextos adecuados con el fin de poder analizar la variación presente en la realización del fonema palatal $/ K /$ del español. Por otra parte, para el estudio del modo de articulación en las manifestaciones aproximantes y semiconsonánticas, se ha incluido un número equivalente de ocurrencias de $\left[\mathrm{j}_{\tau}\right]$, [j] e [i] (30 casos), tanto 
en contexto tónico como en posición átona, para poder establecer una comparación fiable entre las propiedades típicas del sonido consonántico y las del semiconsonántico frente a la vocal.

\subsection{El grado de abertura}

Uno de los aspectos que más llama la atención es el referente al grado de abertura del sonido. Como se sabe, el yeísmo presenta la dificultad añadida de poder realizarse con alófonos que se sitúan en la frontera entre lo que sería un segmento vocálico y uno consonántico; es decir, en numerosas áreas del dominio lingüístico del español se ha detectado una pronunciación que no coincide con un sonido aproximante (consonántico) sino que parece ser más abierto. Esta clase de fonos solo puede corresponder a elementos de tipo semiconsonántico o, en casos más extremos, a otros vocálicos.

De nuevo, nos movemos en terreno complicado, en un continuum de soluciones que abarcan desde [i] hasta $\left[\dot{j}_{\tau}\right]$, cuya delimitación en categorías fonéticas cerradas y objetivas no siempre es sencilla. En este sentido, una parte importante de la bibliografía especializada en fonética española no ofrece orientaciones claras para distinguir acústicamente tales realizaciones, ya que suelen dar la caracterización de la vocal (y de la semiconsonante) en un capítulo aparte y no suelen cruzar los datos con la aproximante. Afortunadamente, hay autores que sí muestran las diferencias entre ellas (cfr. Navarro Tomás, 1982: 49 o Martínez Celdrán y Fernández Planas, 2007: 166): cualquier sonido de tipo
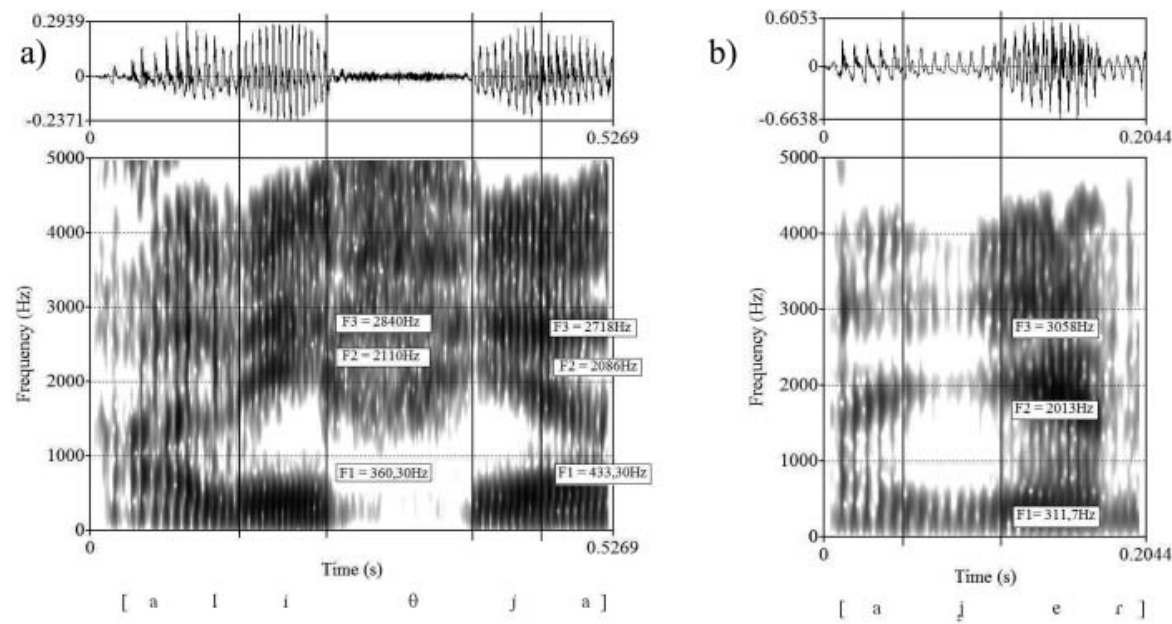

FIGURA 3. Oscilograma y espectrograma de las secuencias Alicia (a) y taller (b). 
vocálico se realiza con una mayor abertura de los articuladores que uno consonántico, lo que, a nivel acústico, debería reflejarse en la frecuencia del primer formante (F1). En efecto, cuanto mayor sea el grado de abertura, más altos van a ser los valores de F1. En el caso de las consonantes, este parámetro parece relacionarse con el modo de articulación (cfr. Delattre, 1951), aunque podría establecerse una comparación entre los valores propios de una vocal y los de una aproximante canónica para trazar el límite entre ambos. Asimismo, otro aspecto que permite la diferenciación es la intensidad, menor en la consonante. Los espectrogramas de la figura 3 muestran estas peculiaridades. Las frecuencias de F1 y F3 en los sonidos [i] e [j] de la palabra Alicia (a) resultan más bajas que las de la consonante $\left[\dot{j}_{\tau}\right]$ de taller (b). Además, se aprecia claramente que la intensidad es mayor en la vocal y en la semiconsonante.

\begin{tabular}{lcccc}
\hline & frec. F1 & frec. F2 & frec. F3 & duración \\
\hline$[$ i] & $360,81 \mathrm{~Hz}$ & $2074,64 \mathrm{~Hz}$ & $2751,17 \mathrm{~Hz}$ & $65,75 \mathrm{~ms}$ \\
[j] & $380,64 \mathrm{~Hz}$ & $2065,47 \mathrm{~Hz}$ & $2765,54 \mathrm{~Hz}$ & $70,04 \mathrm{~ms}$ \\
{$[$ j] } & $342,57 \mathrm{~Hz}$ & $2060,65 \mathrm{~Hz}$ & $2980,42 \mathrm{~Hz}$ & $74,54 \mathrm{~ms}$ \\
\hline
\end{tabular}

TABLA 2. Valores medios de frecuencia y de duración de la vocal palatal alta, la semiconsonante palatal y la consonante aproximante palatal.

Perceptivamente, la diferencia de matiz entre unas realizaciones y otras ([i], [j] e [ $\left.j_{\tau}\right]$ ) no está exenta de dificultad, puesto que se trata de manifestaciones muy similares entre sí. Los datos acústicos recogidos en el experimento al que se hacía referencia anteriormente permiten confirmar la proximidad entre ellas, aunque se pueden apreciar algunas divergencias esperables. Como puede observarse en la tabla 2 (vid. supra), en la que se han resumido los valores medios de frecuencia y duración de la vocal, de la semiconsonante y de la consonante, los datos de frecuencia apuntan a la similitud entre [i] e [j], algo que la estadística también pone de relieve. En efecto, las pruebas de varianza (anova) ${ }^{5}$ indican que no existen diferencias relevantes entre ambos tipos de sonido en cuanto a los valores de frecuencia y tampoco los hay en lo que respecta a su duración, algo en lo que coinciden Martínez Celdrán y Fernández Planas (2007: 169). Sin

5 Se trata de una prueba estadística que permite comparar diversas variables; dicho de un modo más preciso, hace posible determinar si los datos correspondientes a distintos grupos son equiparables o no. En el primer caso, estos grupos pueden identificarse como una única unidad mientras que, en caso contrario, se certifica su distinción. El valor de significación que se considera relevante es igual o inferior a 0,05 , lo que supone un $5 \%$ (o menos) de posibilidades de que los datos resulten demasiado similares como para diferenciar varios grupos y de que tales resultados puedan ser atribuidos al azar. 
embargo, sí se pueden detectar en relación a la consonante. En esta, el primer formante se ubica a una frecuencia significativamente más baja $(F=58,352$, $p<0,0001)$ que en [i] o [j], lo que indica un grado de constricción mayor. Estos datos no hacen más que confirmar la naturaleza consonántica de $\left[\dot{j}_{\text {r }}\right.$ ] frente a los demás, puesto que, como se ha dicho, las consonantes se caracterizan habitualmente por presentar una menor abertura de los articuladores.

El segundo parámetro en el que se observan diferencias relevantes es en la frecuencia del tercer formante. Según explica Delattre (1951: 874), F3 se relaciona con el movimiento del ápice de la lengua: la frecuencia del tercer formante disminuye si este se encuentra elevado. En efecto, los valores resultan mucho más altos en el caso de la consonante que en el resto $(F=88,270$, $p<0,0001$ ), lo que se explica fácilmente si se tiene en cuenta que "la punta de la lengua se apoya contra los incisivos inferiores" (Navarro Tomás, 1982: 129)

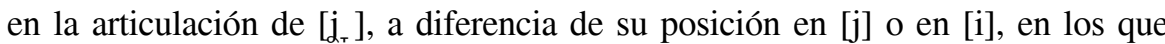
es más elevada. Como era previsible, no se aprecian divergencias importantes a nivel de segundo formante, puesto que todos los segmentos analizados comparten un mismo punto de articulación palatal.

En cuanto a la duración, el estudio estadístico pone de manifiesto que $\left[\dot{j}_{\tau}\right]$ es mucho más larga que la vocal $(F=7542, p<0,001)$ pese a que no se advierten diferencias importantes ni entre esta e [j], ni entre la consonante y la semiconsonante; esta última, de hecho, se sitúa en un punto intermedio.

¿Qué importancia tienen estos datos? Simplemente, teniéndolos presentes, cabe preguntarse si las diferencias entre una realización "abierta", "muy abierta", "extremadamente abierta", "semivocalizada", "con tendencia a semivocal", "muy abierta con tendencia a semivocal", "con tendencia a semiconsonante" (en lo que se refiere a la consonante) o "con tendencia consonántica" (en lo tocante a sonidos a priori semiconsonánticos) son realmente pertinentes, al menos con este nivel de complejidad. Estas caracterizaciones no hacen más que reforzar la idea de continuum fonético entre las realizaciones de los fonemas $/ \mathrm{i} / \mathrm{e} / \mathrm{j}_{\tau} /$ (y $/ K /$, en último término), pero quizás no son tan imprescindibles a la hora de entender la variación diatópica. Por otra parte, no acaban de ser evidentes las propiedades que han permitido tales clasificaciones a partir de la percepción de los encuestadores, puesto que los rasgos acústicos no arrojan pistas claras en este sentido.

Para el estudio de la variación, tanto a nivel dialectal como en un único locutor, sí es importante distinguir nítidamente entre las categorías de vocal, consonante y semiconsonante, pero ir más allá puede suponer entrar en un terreno algo resbaladizo en el que la capacidad de discriminación del encuestador juega un papel demasiado importante y no del todo objetivo. 


\subsection{La sonoridad}

Otro parámetro que se suele tener en cuenta en la descripción de los sonidos que concurren en el fenómeno yeísta es la sonoridad del segmento. Habitualmente, tanto la lateral palatal como la realización aproximante se caracterizan por ser sonoras; sin embargo, otras manifestaciones acústicas que pueden aparecer en esta posición resultan sordas. En general, se trata de fonos que se suelen asociar a áreas del Cono Sur americano (especialmente de Argentina o Uruguay, por ejemplo) o a determinadas regiones de Centroamérica. No obstante, además de la fricativa prepalatal sorda [S], los atlas y demás bibliografía revisada revelan la presencia de otros alófonos sordos en buena parte del dominio lingüístico: $[\phi],[\mathrm{s}],[\mathrm{x}],[\hbar],[\widetilde{\mathrm{ts}}],[\widetilde{\mathrm{t}}]$. Además, también se señala la existencia de otras soluciones semisordas o ensordecidas.

a)

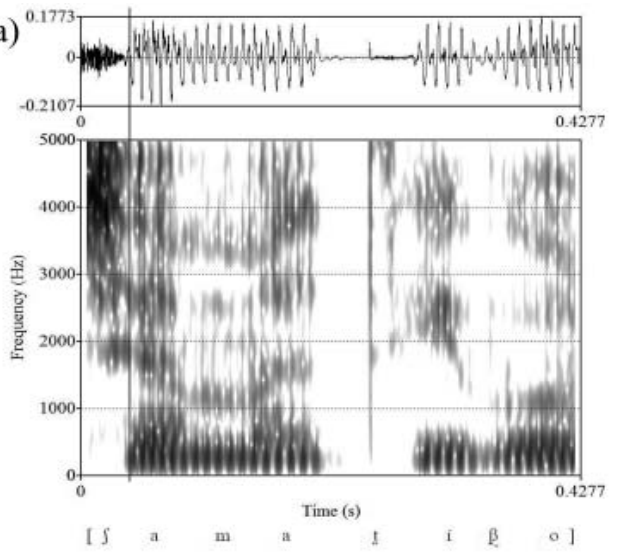

b)

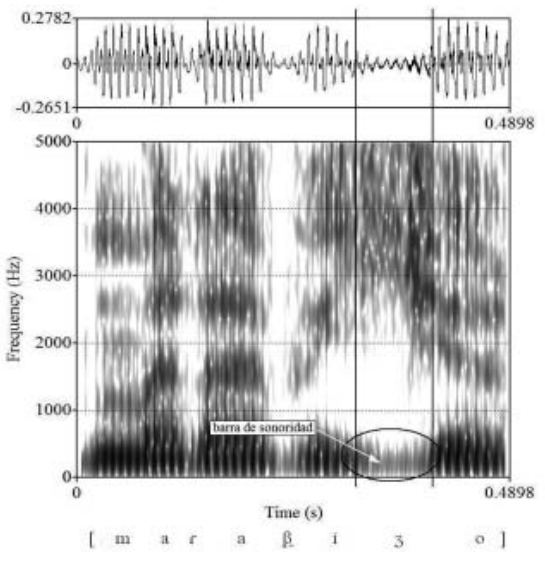

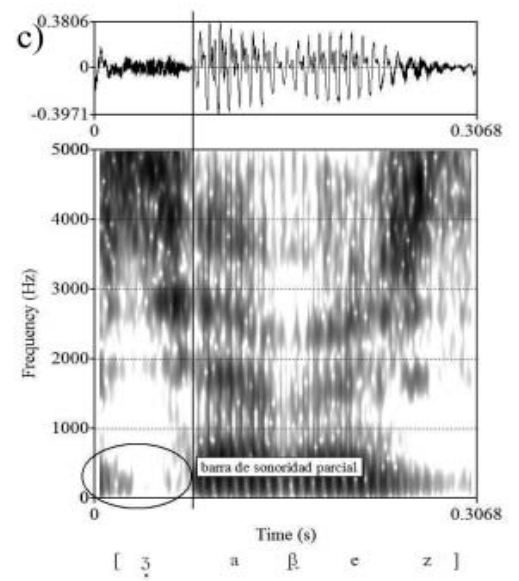

FIGURA 4. Oscilograma y espectrograma de las palabras llamativo(s) (a), maravillo(so) (b) y llaves (c). 
Ciertamente, la sonoridad es un rasgo que suele percibirse sin mayores problemas, aunque en ocasiones la interpretación de la señal puede resultar engañosa. A pesar de ello, su presencia o ausencia es fácilmente comprobable a nivel acústico por la existencia o no de la llamada barra de sonoridad, una zona de mayor intensidad en las frecuencias bajas del espectrograma. En la figura 4 se ofrecen ejemplos que ilustran este aspecto. Así, en la imagen correspondiente a llamativo(s) (a), la consonante inicial es sorda puesto que no presenta energía en las frecuencias más bajas mientras que en maravillo(so) (b), [3] exhibe una barra de sonoridad nítida. En cambio, en llaves (c) se advierte que la barra de sonoridad solo abarca la primera mitad del sonido, lo que indica que se trata de una consonante ensordecida.

La conclusión de todo ello es que, contrariamente a lo que ocurre con el grado de abertura, la sonoridad es una propiedad objetivable que sí permite establecer una gradación pertinente entre una categoría fonética sonora, una sorda y otra que corresponde a un término medio, como ensordecida. De hecho, ante la duda, el nivel de sonoridad se puede demostrar de modo sencillo a partir de una grabación.

\subsection{El rehilamiento}

Un concepto que ha centrado un número importante de estudios es el de rehilamiento. Como explica Navarro Tomás (1934: 274), se trata de la "vibración relativamente intensa y resonante con que se producen ciertas articulaciones", entendiendo como tal "la vibración que estremece los órganos, no sólo en la laringe sino en el punto de articulación, y el efecto acústico que de esto resulta" (Navarro Tomás, 1934: 276). Esta caracterización presenta muchos puntos en común con la de los sonidos de tipo fricativo. De hecho, Quilis (1993: 314), al igual que Martínez Celdrán y Fernández Planas (2007: 54) (los cuales remiten al trabajo de Carrera y Zamora, 1999: 152) no vacila en identificar rehilamiento con fricción:

las dos consonantes palatales $[K]$, o [1] , y [j̃], o [y], pueden dar origen, en la evolución de cada una por separado, o de ambas, como resultado de la desfonologización de la lateral, a la fricativa [3], o [ž], conocida en la filología española con el nombre de rehilada.

Las transcripciones fonéticas de otros autores que emplean habitualmente el AFI, como Malmberg (1965, 1979), Moreno Fernández (2004, 2009) o RAE (2011) también apuntan en esta dirección, puesto que todos ellos utilizan el símbolo propio de la fricativa prepalatal sonora [3] para identificar la realización rehilada sonora. Desde este punto de vista, pues, no parecería haber mayo- 
res dificultades a la hora de reconocer tales manifestaciones, máxime cuando desde la fonética acústica la caracterización de estos sonidos resulta muy clara y se distingue netamente de otra clase de realizaciones (vid. §1.1, figura 1).

El problema, llegados a este punto, estriba en dilucidar si los alófonos documentados se deben considerar realmente sonidos fricativos, puesto que la mayor parte de los atlas lingüísticos presenta lo que aquí se ha pasado a denominar aproximantes como fricativos. Así pues, en determinados casos, no es sencillo establecer cuál es la frontera entre un sonido sin fricción y otro que sí la presenta. Por otra parte, las caracterizaciones existentes en parte de la bibliografía acaban diferenciando entre diversos tipos de sonidos rehilados, atendiendo a la duración y la intensidad de la vibración percibida (baste ver los ejemplos de (7) y (8) para hacerse una idea de la situación). De este modo, se advierten realizaciones como "fricativa prepalatal sonora con rehilamiento", "fricativa prepalatal sonora" o "fricativa palatal sonora" que se identifican con un único fono [3] (transcrito mayoritariamente en los atlas como [ž]), pese a que no presentan rasgos estrictamente equivalentes, como mínimo en lo referente al punto de articulación. De todos modos, siguiendo a Quilis (1993) o Martínez Celdrán y Fernández Planas (2007), parece demostrado que, al hablar de sonidos rehilantes, se debe hacer referencia a consonantes fricativas propiamente dichas, mientras que la ausencia de este adjetivo (o la presencia de su antónimo arrehilante) alude a soluciones de tipo aproximante. Este, en consecuencia, sería un criterio claro y simple para diferenciar realizaciones fonéticas atendiendo a las pruebas que han ofrecido, en los últimos años, diversos estudios en fonética acústica española.

Por otra parte, es importante advertir que la cuestión del rehilamiento no atañe solamente a sonidos fricativos sino también a los de tipo africado. Así, se puede encontrar una "africada palatal central ligeramente rehilada" (ALeCMan), una "africada palatal central sonora con rehilamiento" (Atlas Lingüístico de México, Alvar, 2001b, González Salgado, 2005-2010), una "africada palatal central sonora con el momento fricativo prolongado y rehilado" (ALEICan, Atlas Lingüístico de Castilla y León, ALEA, ALECant, Alvar, 2001b: 831), una "africada palatal rehilada muy relajada" (Atlas Lingüístico de México) o una "africada fuertemente rehilada" (Atlas Lingüístico de México ${ }^{6}$.

De todas formas, pese a que la cantidad de matices pueda parecer algo agobiante, hay que tener presente que estos responden a un factor objetivo que apunta a la existencia del continuum de variación del que se ha hablado anteriormente. En efecto, tanto en el caso de las realizaciones fricativas como en el

\footnotetext{
${ }^{6}$ Desde luego no hay que olvidar que, a estas propiedades, se les pueden añadir otras relativas a la sonoridad o al grado de abertura, lo que complica todavía más una posible sistematización. Se encuentran, por ejemplo, casos de "alveolo-prepalatal central muy rehilada y sin labialización", "palatal fricativa sonora rehilada ensordecida", "dentoalveolar coronal fricativa sonora asibilada y rehilada", entre otros.
} 
de las africadas, es posible encontrar ejemplos abundantes de sonidos que suponen un punto intermedio. Estos segmentos se caracterizan por presentar una estructura formántica más o menos clara y, simultáneamente, energía desordenada en frecuencias altas; es decir, se superponen los rasgos propios de aproximantes y fricativas.

Algo parecido ocurre con las africadas, en las que el elemento que sigue a la fase de cierre de los articuladores, que habitualmente debe presentar fricción para tener la consideración de africada (cfr. Ladefoged y Maddieson, 1996: 90), puede insinuar la presencia de formantes. En ocasiones, incluso puede identificarse más con un elemento aproximante que con uno fricativo, hasta el punto de que algunos autores hablan de alófonos oclusivos de doble articulación más que de africadas propiamente dichas (cfr. Martínez Celdrán y Fernández Planas, 2001, 2002, 2007).

En estos casos, las herramientas de análisis acústico son de gran ayuda para poder definir el tipo de manifestación. Así pues, el estudio de los espectrogramas obtenidos a partir del experimento realizado hace posible establecer algunas diferencias relevantes: evidentemente, la primera se da entre los elementos fricativos y los africados por la presencia o ausencia de un periodo de silencio previo a la fricción (fase de cierre de los articuladores u oclusión). Una vez despejado este extremo, hay que distinguir aquellos segmentos cuya estructura responde estrictamente a energía dispersa (fricativos) de los que permiten observar cierta presencia de formantes, lo que supone hablar de un tipo de realización intermedia entre fricativos y aproximantes: aproximantes fricativizadas o fricativas aproximantizadas/espirantizadas, según los rasgos que predominen.

En lo que se refiere a las africadas, las especificaciones son algo más complejas: se advierten consonantes africadas que responden a la caracterización canónica de esta clase de sonidos mientras que, en otros casos, hay que contemplar la presencia de un elemento aproximante en lugar de uno fricativo. Teniendo en cuenta las explicaciones de Ladefoged y Maddieson (1996) y las reflexiones de Martínez Celdrán y Fernández Planas (2001, 2007), este tipo de elementos deberían clasificarse como oclusivos con doble articulación. Por último, se pueden detectar algunos casos en los que la fase fricativa deja entrever formantes aunque sin eliminar la fricción: se podrían identificar con las realizaciones que la bibliografía denomina "ligeramente rehiladas" y que aquí preferimos describir como aproximantizadas o espirantizadas. La figura 5 incluye ejemplos de cada una de estas variantes: llena (a) supone una manifestación típicamente fricativa; bollería (b), una aproximante fricativizada; llevar (c), una africada; estallar (d), incluye una oclusiva de doble articulación y, finalmente, llamar (e), una africada espirantizada.

Otra cuestión relevante que surge al analizar esta clase de segmentos fricativos es la de su punto de articulación. En las obras revisadas se mencionan 
a)
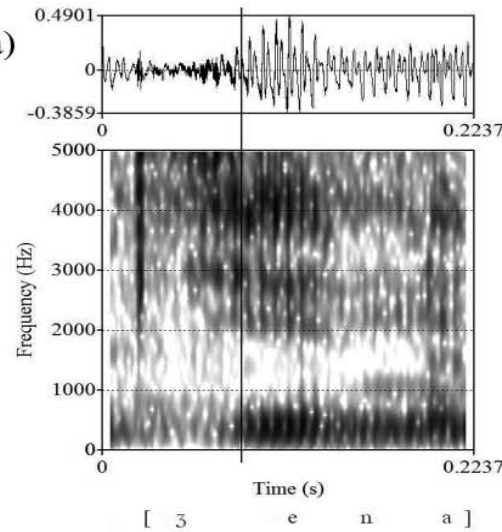

c)

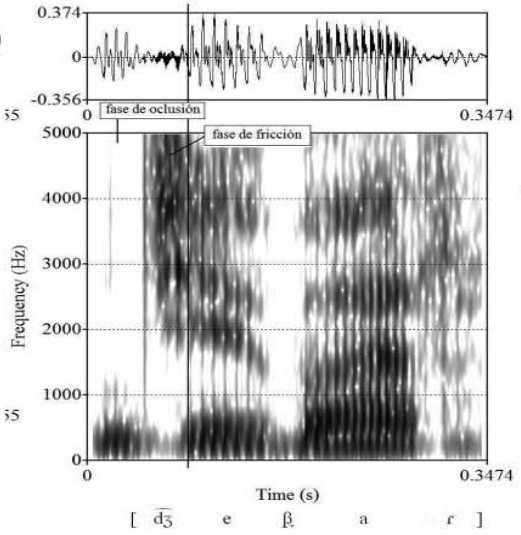

b)

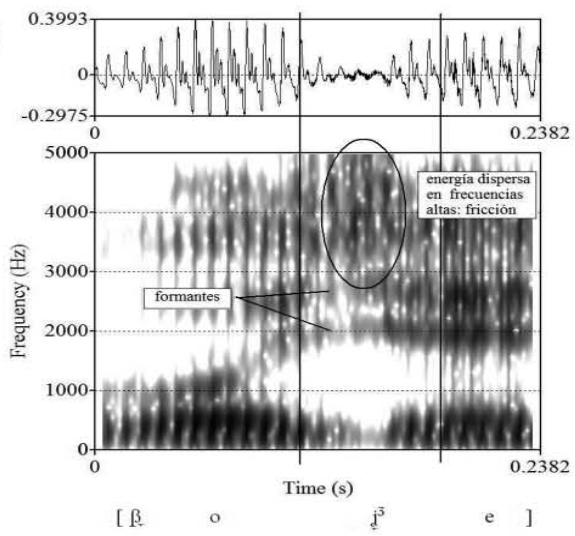

d)
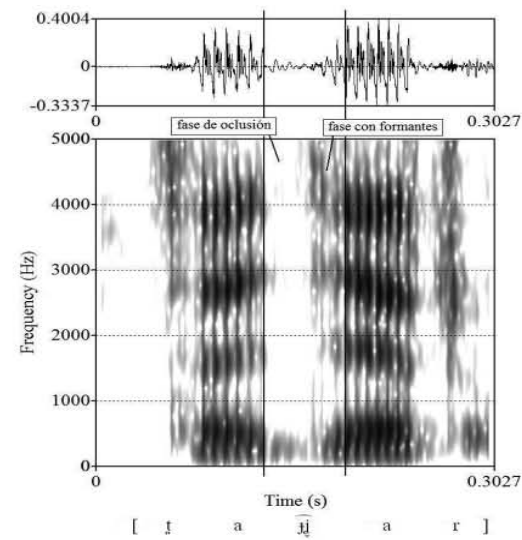

e)

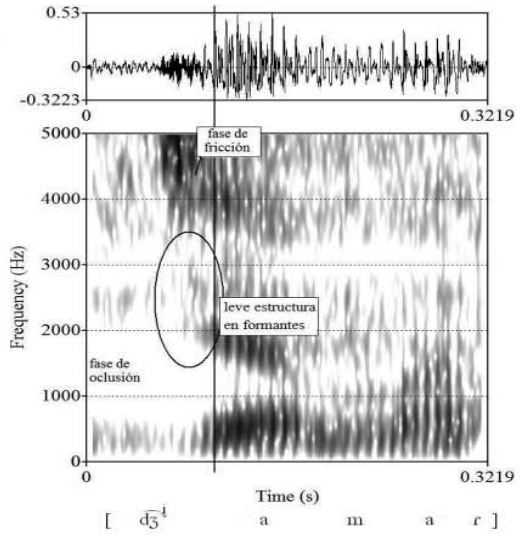

FIGURA 5. Oscilogramas y espectrogramas de las palabras llena (a), bolle(ría) (b), llevar (c), (es)tallar (d) y llamar (e). 
manifestaciones fonéticas prepalatales, prepalato-alveolares y alveolares. En cambio, si se atiende a las transcripciones de los autores que emplean el AFI (algo más homogéneas en este sentido), parece que se trata inequívocamente de elementos de tipo prepalatal, ya que se representan como [3] o [J], en función de su sonoridad. Si se tratara de consonantes de tipo palatal los símbolos hubieran debido ser [j] y [ç]. De hecho, Ladefoged y Maddieson (1996: 165) comentan que "less than $5 \%$ of the languages of the world include ç in their inventory [...]. The voiced palatal fricative $j$ is even more rare". Además, estos sonidos no son sibilantes, mientras que las descripciones halladas en la bibliografía, directa o indirectamente, sugieren esta naturaleza. Por lo tanto, se ha optado por pensar que se trata de elementos fricativos prepalatales, tal como aparecen caracterizados en Malmberg (1979) o en Moreno Fernández (2004, 2009). Como síntesis de lo expuesto hasta aquí, la figura 6 muestra las diversas clases de alófonos con elemento fricativo que se han podido atestiguar a partir del experimento fonético llevado a cabo y que, asimismo, recogen, sistematizándolos, los hallados en el corpus bibliográfico:

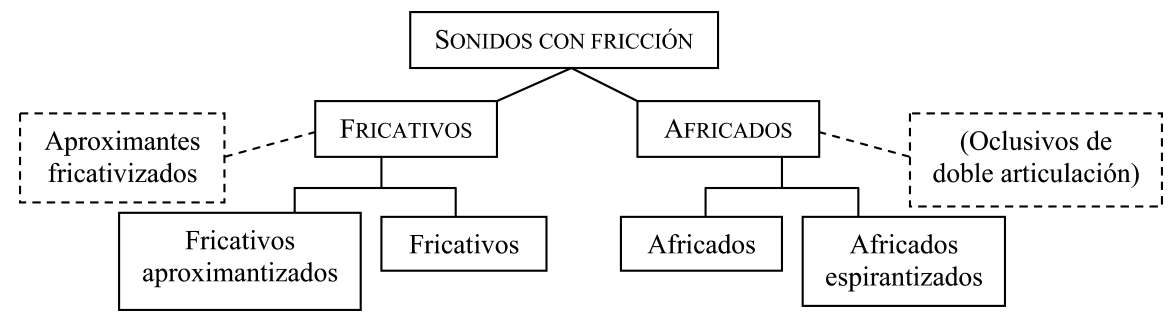

FIGURA 6. Resumen de los sonidos con fricción correspondientes a soluciones rehiladas.

\subsection{La presencia de sonidos oclusivos}

En pocas ocasiones se tienen en cuenta realizaciones de tipo oclusivo entre los alófonos contemplados para $/ K /$. En efecto, los más habituales suelen ser aproximantes, fricativos o africados; sin embargo, la revisión de la bibliografía permite observar la existencia de soluciones cuya descripción se aparta de las características propias de estos sonidos y que, en cambio, encajan con las propiedades de las oclusivas. En este sentido, las anteriormente mencionadas oclusivas palatales de doble articulación, descritas en el apartado 3.3, deben incluirse aquí, puesto que, estrictamente, no exhiben una segunda fase que coincida con las particularidades de las soluciones africadas.

No obstante, el problema no se detiene en este punto sino que se extiende a algunas variantes documentadas en el ALEANR, el ALeCMan y el ALEA en las 
que se puede entrever una alusión velada a realizaciones de tipo oclusivo. Ciertamente, en algunas poblaciones de Huesca (Puebla de Castro), de Ciudad Real (Cabezarados) y Córdoba (Cañete de las Torres), se alude a un alófono del tipo [pj] o [dj] $]^{7}$. Esta transcripción pone de manifiesto la existencia de una fase de cierre de los articuladores (oclusión, por lo tanto) seguida de un elemento palatal semiconsonántico que hace pensar en una fase con estructura formántica, al uso de las consonantes aproximantes. Esta caracterización coincide plenamente con las llamadas oclusivas palatales de doble articulación ([jj] $)$ y quién sabe si, debido a la duración de esta segunda parte del sonido, no se podría llegar a identificar el elemento palatal con el periodo de abertura de los articuladores, tal como explica Quilis (1993: 298). Este autor, al describir las africadas sonoras del español advierte que una de las manifestaciones fonéticas posibles

no presenta momento fricativo, siendo la duración media del momento explosivo de 4,5cs [...]; pero realmente, más que fricación, es la explosión de la palatal. Su zona articulatoria es más amplia que en las otras realizaciones, tanto sonora como sorda, y su articulación es más adherente; de ahí la tendencia a mostrarse como una verdadera oclusiva palatal, sin fricación.

En consecuencia, debe tomarse en consideración la posibilidad de encontrar alófonos oclusivos de la consonante palatal [j], especialmente en contextos iniciales o tras nasal (contextos análogos a los de ocurrencia de las demás oclusivas del español $)^{8}$. La comprobación, nuevamente, resulta sencilla a partir del análisis espectrográfico, un recurso que permite dilucidar sin problemas si existen argumentos para poder clasificar la señal en la categoría de las consonantes africadas o en la de las oclusivas. Tal como se puede comprobar en la figura 7, las diferencias entre un tipo de solución y otro suelen poder observarse de forma clara. En efecto, en (a) la realización de $/ K /$ para llaneza exhibe un periodo de fricción evidente tras la fase de cierre, algo que no sucede en llevando (b), ejemplo en el que solo se advierte la oclusión:

\footnotetext{
${ }^{7}$ Este tipo de soluciones también pueden inferirse de las notaciones halladas en otras obras dedicadas a otras regiones, como en Quilis y Casado (2008), o, de modo más general, Malmberg (1965: 106).

8 También RAE (2011: 193) reconoce esta variante, más frecuente, según se explica, “en el área leonesa de la península ibérica”.
} 
a)

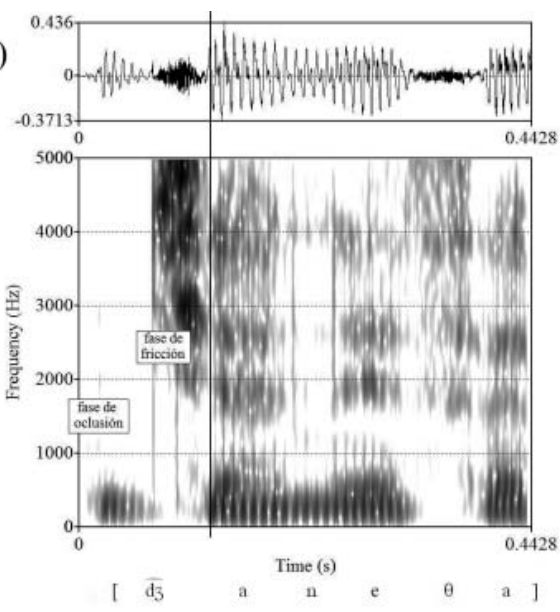

b)

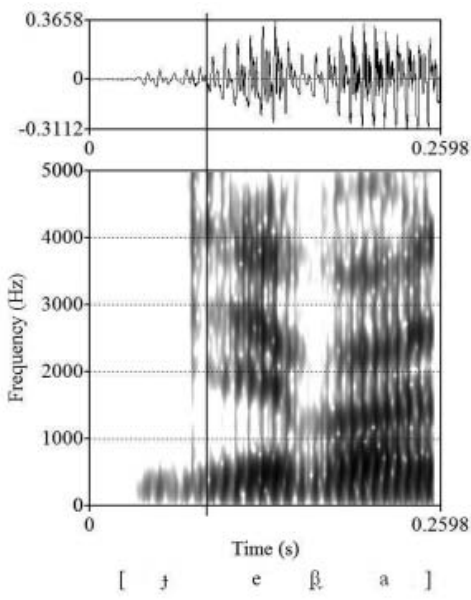

FigURA 7. Oscilograma y espectrograma de las palabras llaneza (a) y lleva(ndo) (b).

\section{HACIA UNA PROPUESTA DE TRANSCRIPCIÓN}

Las observaciones planteadas hasta aquí ponen en cuestión dos ideas fundamentales: en primer lugar, el criterio perceptivo en la documentación de variantes fonéticas dialectales puede resultar impreciso y estar sujeto a interpretaciones sesgadas, fruto de las dificultades propias del acto de habla (presencia de ruidos, problemas de vocalización, malentendidos, etc.); y, en segundo lugar, el apoyo de los instrumentos de análisis fonético experimental puede implicar una mayor precisión en la categorización de las soluciones detectadas.

Estas dos constataciones apuntan a una conclusión evidente: la percepción conlleva una serie de dificultades intrínsecas al proceso de comunicación humana, lo que supone la aparición de obstáculos importantísimos para lograr una sistematización clara de las realizaciones que constituyen el input del encuestador. Por lo tanto, no parece razonable que su interpretación subjetiva sea el único parámetro bajo el cual deban establecerse las diferenciaciones en cuanto al inventario de categorías fonéticas apreciadas. Por muy bien preparado que esté el investigador, existen factores externos a él que pueden modificar la discriminación del sonido, algo que debería poder evitarse con un apoyo técnico y un análisis fonético a posteriori de las respuestas obtenidas, tal como se está haciendo en estudios más recientes sin que se advierta ninguna merma en la calidad de las respuestas (Alvar, 2000a, 2000b, 2001a, 2001b, por ejemplo).

Este hecho, además, supondría la obligación de establecer unos criterios fonéticos claros a la hora de interpretar los datos, tanto a nivel perceptivo como acústico. En este sentido, no dejan de ser relevantes las reflexiones de los apar- 
tados anteriores, en las que quedaba patente que, con un análisis experimental añadido, se llega a una sistematización más objetiva de los estímulos, dado que permite discernir entre los rasgos que resultan pertinentes y los que no lo son.

Por otra parte, debe hacerse notar que existen problemas de difícil solución incluso con el empleo de las tecnologías de análisis del habla. Un ejemplo muy evidente lo constituye la raíz del fenómeno yeísta, es decir, la confusión entre $[\kappa]$ e $\left[j_{*}\right]$. La percepción de un sonido u otro está estrechamente ligada a la naturaleza, yeísta o no, del receptor de la señal: un hablante yeísta tenderá a no reconocer una lateral palatal y a identificarla con una aproximante, simplemente porque la primera ya no existe en su sistema fonológico ${ }^{9}$. La distinción es complicada incluso para hablantes distinguidores, como se ha comprobado en un pequeño experimento piloto (Rost, 2011: 184-187) ${ }^{10}$. El estudio acústico del sonido tampoco contribuye a clarificar la cuestión, más bien confirma que la confusión resulta inevitable dada la inexistencia de parámetros que hagan posible establecer una diferenciación clara entre ambas realizaciones. La conclusión, en este sentido, apuntaría a la práctica desaparición de las divergencias que permitían la discriminación entre $[K]$ e $\left[\dot{j}_{\tau}\right]$.

Asimismo, como se había comentado al inicio de este trabajo, hay otro factor metodológico que podría facilitar el análisis de las variantes diatópicas pero que en realidad viene a oscurecerlo: el sistema de transcripción fonética. Quizás el mayor problema que reviste la comparación de las variantes fonéticas en español reside precisamente en la forma de notación gráfica de las soluciones dialectales. De hecho, el empleo de unos criterios fonéticos objetivos en el estudio de los sonidos también tendría consecuencias a nivel gráfico, ya que supondría la eliminación de distinciones poco claras o directamente ambiguas y contradictorias como las reseñadas en el apartado 2.

Por este motivo, la existencia de unos parámetros estrechamente relacionados con los rasgos acústicos de los sonidos debe contribuir necesariamente a reducir el volumen de variantes inventariadas (muchas de las cuales parecen cuestionables) y, por lo tanto, también debe llevar a una simplificación de los símbolos fonéticos empleados. Huelga decir que tal clarificación en la nomenclatura resultaría inoperante sin una voluntad de unificar criterios en el empleo

\footnotetext{
${ }^{9}$ Investigaciones recientes, no obstante, indican que los hablantes yeístas son capaces de producir el sonido $[K]$ (de hecho, lo hacen) pero como alófono de /l/ ante semiconsonante palatal, en ejemplos como los de las voces caliente o Emilio (cfr. Rost Bagudanch, 2010, 2011).

${ }^{10}$ En dicho experimento se pedía a seis hablantes distinguidores de catalán (lengua que conserva la diferenciación fonológica) que establecieran cuáles de los estímulos que se les iban a mostrar correspondían a una lateral palatal y cuáles a una aproximante palatal. Los resultados indicaban que no había una tendencia clara en la percepción del sonido y que las confusiones eran generales en todos los sujetos. Cabe señalar que los seis eran personas con formación filológica $\mathrm{y}$, por lo tanto, conocedores de las nociones técnicas y teóricas relacionadas con la fonética.
} 
de estos símbolos: en estos momentos, las confusiones no se centran en el dilema de qué alfabeto fonético se utiliza sino en cómo se hace. Se han aducido ejemplos en los que, pese a tratarse siempre del sistema de la $R F E$, las grafías no coinciden, lo que hace muy complicada la interpretación de la información (baste recordar los casos contenidos desde (2) hasta (8)).

Precisamente por esta razón, y teniendo en cuenta la existencia, cada vez más frecuente, de investigaciones que emplean el AFI como sistema de notación, no sería descabellado adoptar este alfabeto fonético, máxime si se considera que los trabajos centrados en otras lenguas coinciden en su uso. De hecho, se facilitaría sobremanera la comparación con otros sistemas fonéticos, especialmente en el caso de otras lenguas románicas con las que se comparten tendencias y fenómenos lingüísticos.

Lo que se ha ido mostrando hasta aquí lleva irremediablemente al cuestionamiento de la heterogeneidad de los datos disponibles para la investigación dialectal. En realidad, este hecho ha estimulado una reflexión científica para intentar dotar de algo más de coherencia una información tan detallada como dispersa en el caso del yeísmo. Esta reflexión se ha sustentado en varios ejes para recabar una visión de conjunto sólida de la situación y ofrecer una solución unitaria y lógica; por lo tanto, se ha acudido, por una parte, a la revisión bibliográfica y, por otra, a la comprobación experimental. El propósito último ha sido el de hallar equivalencias claras y objetivables entre las formas reseñadas en el corpus, algo imprescindible si se quiere entender el alcance del fenómeno yeísta, sus consecuencias a nivel fonético-fonológico y la dirección que puede tomar este proceso, que se ha coincidido en considerar como un cambio fonológico en marcha.

Así pues, en primer lugar se ha procedido a un examen atento de la nomenclatura empleada para designar las diferentes variantes lo que, por consiguiente, ha significado revisar la naturaleza fónica que se les atribuye. Como se ha podido comprobar, esta información también se ha contrastado con trabajos centrados en la descripción fonética del español tanto a nivel articulatorio como acústico (Navarro Tomás, 1982; Quilis, 1981 y 1993; Aguilar, 1999; Hualde, 2005 o RAE, 2011) además de otros que tratan la naturaleza de los sonidos del habla de forma más universal (cfr. Malmberg, 1979; Ladefoged y Maddieson, 1996 o Ladefoged, 2001, por ejemplo). De ellos se ha podido extraer información muy valiosa acerca del tipo de alófonos que es posible distinguir acústica y perceptivamente y sobre cuáles son sus propiedades más probables en español (especialmente en lo tocante al punto de articulación).

Asimismo, ha resultado muy interesante establecer una comparación entre las obras del mismo corpus, especialmente aquellas que sí incluyen datos procedentes del estudio fonético experimental del sonido (como el ALEC, el Atlas Lingüístico de México o Alvar, 2000a, 2000b, 2001a y 2001b). Estas últimas 
demuestran de modo fehaciente que el empleo de esta clase de recursos no solo no afecta la calidad de las respuestas obtenidas sino que, por el contrario, resulta un complemento importantísimo para la valoración y categorización de los estímulos percibidos. De hecho, el análisis a posteriori de las grabaciones faculta para una clasificación más consciente y clara de la señal.

De todos modos, el punto de partida que ha permitido dar forma a una propuesta de homogeneización de los datos ha sido el análisis acústico del habla, cuyos resultados se han ido presentando anteriormente (vid. §3). Antes de proseguir con la exposición, cabe subrayar que los casos obtenidos en las grabaciones han hecho posible rastrear la práctica totalidad de las variantes fonéticas atestiguadas por la bibliografía en los distintos puntos del dominio lingüístico del español (y no solo en un único informante sino en los tres a los que se ha recurrido); así, se han podido estudiar empíricamente buena parte de las soluciones sobre las que se extienden los estudios dialectales. En efecto, el experimento evidencia algunos de los rasgos más significativos de los alófonos de $/ \mathrm{K} /$ y permite considerar cuáles de ellos pueden entenderse como relevantes y cuáles no; es decir, ha posibilitado una distinción bastante neta entre las características objetivas del sonido y las apreciaciones inevitablemente más subjetivas. Atendiendo a las primeras, se ha elaborado una propuesta preliminar de equivalencias fonéticas entre los símbolos empleados en buena parte de los atlas (RFE) y los del AFI, que se reproduce en la tabla 3 (infra). Estas correspondencias responden a una voluntad de sistematizar los datos disponibles basándose en las propiedades intrínsecas del sonido en cuanto onda sonora, que es la que, en buena parte, determina la impresión perceptiva que tal sonido puede desencadenar a nivel individual.

\section{CONCLUSIONES}

Así pues, para alcanzar un mayor grado de efectividad en el estudio de las variantes fonéticas dialectales, en general, y del yeísmo en particular, se revela indispensable unificar los criterios empleados tanto en la representación gráfica de las diversas soluciones detectadas como en el valor que se les debe dar en cuanto realizaciones fonéticas. En este sentido, cabe preguntarse si la ingente cantidad de matices que se han ido estableciendo a lo largo de los años es realmente relevante o si constituye más bien una información interesante pero que, quizás, acaba por dificultar la labor del investigador más que facilitarla. Probablemente, el empleo de técnicas de análisis fonético experimental que no interfieran en la espontaneidad de las respuestas permitiría esclarecer si las diferencias de detalle que se recogen en los atlas y obras afines resultan significativas o si, por el contrario, complican el estudio comparativo entre zonas dialectales e, incluso, entre sistemas lingüísticos. 


\begin{tabular}{|c|c|c|c|}
\hline $\begin{array}{l}\text { Modo de } \\
\text { articulación }\end{array}$ & Descripción & Símbolo RFE & $\begin{array}{c}\text { Simbolo } \\
\text { AFI }\end{array}$ \\
\hline \multirow{2}{*}{$\begin{array}{l}\text { Vocales y } \\
\text { glides }\end{array}$} & Vocal palatal alta & [i] & [i] \\
\hline & Semiconsonante palatal alta & [j] & [j] \\
\hline \multirow[t]{4}{*}{ Aproximantes } & Aproximante palatal sonora & [y] & {$\left[\dot{j}_{\tau}\right]$} \\
\hline & Aproximante palatal ensordecida & [y] & {$\left[\dot{j}_{0}\right]$} \\
\hline & $\begin{array}{l}\text { Aproximante palatal sonora } \\
\text { fricativizada }\end{array}$ & 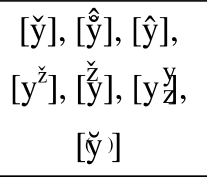 & {$\left[j^{3}\right]$} \\
\hline & $\begin{array}{l}\text { Aproximante palatal sonora } \\
\text { fricativizada ensordecida }\end{array}$ & {$\left[\check{y}_{0}\right],[y ̊],\left[y_{0}\right]$} & {$\left[j_{\text {a }}^{3}\right]$} \\
\hline \multirow[t]{4}{*}{ Laterales } & Lateral alveolar sonora & [1] & [1] \\
\hline & Lateral palatalizada sonora & [1'] & {$\left[\mathrm{l}^{\mathrm{j}}\right]$} \\
\hline & Lateral palatal sonora & [l] & {$[K]$} \\
\hline & Lateral velarizada & [t] & [1] \\
\hline \multirow[t]{10}{*}{ Fricativas } & Fricativa bilabial sorda & {$[\varphi]$} & {$[\phi]$} \\
\hline & Fricativa alveolar sorda & [s] & [s] \\
\hline & Fricativa alveolar sonora & {$[\mathrm{z}]$} & [z] \\
\hline & Fricativa prepalatal sorda & {$[\check{s}]$} & [S] \\
\hline & Fricativa prepalatal sonora & [ž], [ź], [yây, & [3] \\
\hline & $\begin{array}{l}\text { Fricativa prepalatal sonora } \\
\text { aproximantizada/espirantizada }\end{array}$ & {$\left[z^{\check{y}}\right],\left[\check{y ̆}_{0}^{j}\right],\left[\check{z}^{j}\right]$} & {$\left[3^{\dot{j}}\right]$} \\
\hline & Fricativa prepalatal ensordecida & {$[\overline{\mathrm{z}}],[\mathrm{y}]$} & [3. $]$ \\
\hline & Fricativa velar sorda & {$[\mathrm{x}]$} & {$[\mathrm{x}]$} \\
\hline & Fricativa faríngea sorda & [h] & {$[\hbar]$} \\
\hline & Fricativa faríngea sonora & [6] & {$[\mathrm{Y}]$} \\
\hline \multirow[t]{7}{*}{ Africadas } & Africada alveolar sorda & {$[\hat{\mathrm{s}}]$} & {$[\widehat{\mathrm{ts}]}$} \\
\hline & Africada alveolar sonora & {$[\hat{z}]$} & [dz] \\
\hline & Africada alveolar ensordecida & {$[\hat{z}]$} & {$[\overline{d z]}$} \\
\hline & Africada prepalatal sorda & 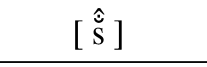 & {$[\overline{\mathrm{t} J]}$} \\
\hline & Africada prepalatal sonora & {$[\hat{z}]$} & {$[\mathrm{d} \overline{3}]$} \\
\hline & Africada palatal sorda & {$[\mathrm{t} s ̌],[\hat{s}]$} & [tç] \\
\hline & Africada palatal sonora & {$[\hat{y}],[\hat{z}],[\hat{y}]$} & [ \\
\hline
\end{tabular}

TABLA 3. Correspondencias entre los símbolos del alfabeto fonético de la RFE y los del AFI para el fenómeno yeísta (se han incluido los alófonos más frecuentes). 


\begin{tabular}{|c|c|c|c|}
\hline $\begin{array}{l}\text { Modo de } \\
\text { articulación }\end{array}$ & Descripción & Símbolo RFE & $\begin{array}{c}\text { Símbolo } \\
\quad A F I\end{array}$ \\
\hline & Africada palatal ensordecida & [ŷ̀] & {$\left[\longdiv { \mathrm { d } _ { 0 } }\right]$} \\
\hline & $\begin{array}{l}\text { Africada palatal sonora larga o } \\
\text { intensa }\end{array}$ & $\begin{array}{c}\hat{y}],[\hat{z}],[\hat{y}], \\
{[\hat{y}]}\end{array}$ & [d $\overline{3:}]$ \\
\hline \multirow[t]{3}{*}{ Oclusivas } & $\begin{array}{l}\text { Oclusiva palatal sonora de doble } \\
\text { articulación }\end{array}$ & --- & [fid] \\
\hline & Oclusiva palatal & [pj], [dj], [gj] & [f] \\
\hline & Oclusiva palatal ensordecida & --- & {$\left[\mathrm{f}_{\mathrm{o}}\right]$} \\
\hline
\end{tabular}

Por este motivo, se considera que el recurso al estudio acústico de los sonidos del habla puede aportar una información valiosísima a la hora de asociar los estímulos a una categoría fonética concreta, algo que la discriminación a nivel perceptivo no siempre puede garantizar porque depende de la interpretación de un sujeto receptor. La aplicación de tales métodos y, en definitiva, la colaboración entre fonética experimental y dialectología debe allanar el camino para delimitar claramente el inventario de soluciones fónicas y, sobre todo, para deshacer ambigüedades y confusiones. La consecuencia última será la obtención de una clasificación de las variantes más reducida, sí, pero más sistemática y homogénea.

\section{BIBLIOGRAFÍA}

Aguilar, Lourdes (1999): "Hiatus and Diphtong: Acoustic Cues and Speech Differences", Speech Communication, 28, pp. 57-74.

Alcina, Juan y Blecua, José Manuel (1975): Gramática española, Barcelona, Ariel.

Alvar, Manuel (1975): Atlas Lingüístico y Etnográfico de las Islas Canarias, Las Palmas de Gran Canaria, Cabildo Insular.

Alvar, Manuel (1979-1983): Atlas Lingüístico y Etnográfico de Aragón, Navarra y La Rioja, Madrid, La Muralla.

Alvar, Manuel (dir.) (1996a): Manual de dialectología hispánica. El español de España, Barcelona, Ariel.

Alvar, Manuel (dir.) (1996b): Manual de dialectología hispánica. El español de América, Barcelona, Ariel.

Alvar, Manuel (1999): Atlas Lingüístico de Castilla y León, Salamanca, Junta de Castilla y León.

Alvar, Manuel (2000a): El español de la República Dominicana. Estudios, encuestas y textos, Madrid, Universidad de Alcalá, La Goleta.

Alvar, Manuel (2000b): El español del Sur de Estados Unidos. Estudios, encuestas y textos, Madrid, Universidad de Alcalá, La Goleta.

Alvar, Manuel (1923-2001a): Atlas Lingüístico y Etnográfico de Andalucía, Madrid, Arco/Libros. Alvar, Manuel (1923-2001b): Atlas Lingüístico y Etnográfico de Cantabria, Madrid, Arco/Libros. 
Alvar, Manuel (2001a): El español en Paraguay. Estudios, encuestas y textos, Madrid, Universidad de Alcalá, Agencia Española de Cooperación, La Goleta.

Alvar, Manuel (2001b): El español de Venezuela. Estudios, encuestas y textos, Madrid, Universidad de Alcalá, La Goleta.

Delattre, Pierre (1951): “The Physiological Interpretation of Sound Spectrograms”, PMLA, 66, 5, pp. 864-875.

Flórez, Luis (1981-1983): Atlas Lingüístico-Etnográfico de Colombia, Bogotá, Instituto Caro y Cuervo.

Fontanella de Weinberg, Beatriz (coord.) (2000): El español de Argentina y sus variedades regionales, Buenos Aires, Edicial.

García Mouton, Pilar y Moreno Fernández, Francisco (2003): Atlas Lingüístico (y etnográfico) de Castilla-La Mancha, Universidad de Alcalá. Disponible en: <http://www2.uah.es/alecman>.

González Salgado, José Antonio (2005-2010): Cartografía lingüística de Extremadura. Disponible en: <http://www.geolectos.com/index.htm>.

Hualde, José Ignacio (2005): The Sounds of Spanish, Cambridge, Cambridge University Press.

Ladefoged, Peter (2001): Vowels and Consonants. An Introduction to the Sounds of Languages, Oxford, Blackwell Publishers.

Ladefoged, Peter \& Maddieson, Ian (1996): The Sounds of the World's Languages, Oxford, Blackwell Publishing.

Lipski, John (1996): El español de América, Madrid, Cátedra.

Lope Blanch, Juan M. (1990): Atlas Lingüístico de México, México DF, Fondo de Cultura Económica.

Malmberg, Bertil (1965): Estudios de fonética hispánica, Madrid, CSIC.

Malmberg, Bertil (1979): La fonética, $8^{a}$ ed., Rivadavia, Editorial Universitaria de Buenos Aires.

Martínez Celdrán, Eugenio (2004): "Problems in the Classification of Approximants", Journal of the Acoustic Society of America, 34, 2, pp. 201-210.

Martínez Celdrán, Eugenio y Fernández Planas, Ana M. ${ }^{a}$ (2001): "Propuesta de transcripción para la africada palatal sonora del español", Estudios de Fonética Experimental, 11, pp. 173-190.

Martínez Celdrán, Eugenio y Fernández Planas, Ana M. a (2002): "Características fonéticas de la africada palatal sonora del español", en M. Tadea Díaz Hormigo (ed.), IV Congreso de Lingüística General: Cádiz, del 3 al 6 de abril de 2000, IV, Cádiz, Servicio de Publicaciones de la Universidad de Cádiz y Servicio de Publicaciones de la Universidad de Alcalá, pp. 17511761.

Martínez Celdrán, Eugenio y Fernández Planas, Ana M. ${ }^{a}$ (2007): Manual de fonética española. Articulaciones y sonidos del español, Barcelona, Ariel.

Moreno Fernández, Francisco (2004): "Cambios vivos en el plano fónico del español. Variación dialectal y sociolingüística", en Rafael Cano Aguilar (coord.), Historia de la lengua española, Barcelona, Ariel, pp. 973-1010.

Moreno Fernández, Francisco (2009): La lengua española en su geografía, Madrid, Arco Libros.

Navarro Tomás, Tomás (1934): "Rehilamiento", Revista de Filología Española, V, pp. 274-279.

Navarro Tomás, Tomás (1982): Manual de pronunciación española, 21 a ed., Madrid, CSIC.

Quilis, Antonio (1981): Fonética acústica de la lengua española, Madrid, Gredos.

Quilis, Antonio (1993): Tratado de fonología y fonética españolas, $2^{a}$ ed., Madrid, Gredos.

Quilis, Antonio y Celia Casado (2008): La lengua española en Filipinas. Historia. Situación actual. El chabacano. Antología de textos, Madrid, CSIC.

RAE (2010): Ortografía de la lengua española, Madrid, Espasa.

RAE (2011): Nueva gramática de la lengua española. Fonética y fonología, Barcelona, Espasa.

Rost Bagudanch, Assumpció (2010): "Algunas consideraciones sobre el proceso de palatalización de la consonante lateral en español”, Interlingüística, 20. 
Rost Bagudanch, Assumpció (2011): Variación en los procesos de palatalización de yod segunda (o cómo la sincronía permite la explicación de la diacronía), Girona, Universitat de Girona, tesis doctoral. Disponible en: <http://hdl.handle.net/10803/31860>.

Zamora Vicente, Alonso (1967): Dialectología española, $2^{\mathrm{a}}$ ed., Madrid, Gredos.

Fecha de recepción: 21 de noviembre de 2011

Fecha de aceptación: 9 de mayo 2012 